\title{
Links between genome replication and chromatin landscapes
}

\author{
Joana Sequeira-Mendes and Crisanto Gutierrez* \\ Centro de Biologia Molecular Severo Ochoa, CSIC-UAM, Nicolas Cabrera 1, Cantoblanco, 28049 Madrid, Spain
}

Received 19 February 2015; revised 27 March 2015; accepted 1 April 2015; published online 6 April 2015.

*For correspondence (e-mail cgutierrez@cbm.csic.es)

\begin{abstract}
SUMMARY
Post-embryonic organogenesis in plants requires the continuous production of cells in the organ primordia, their expansion and a coordinated exit to differentiation. Genome replication is one of the most important processes that occur during the cell cycle, as the maintenance of genomic integrity is of primary relevance for development. As it is chromatin that must be duplicated, a strict coordination occurs between DNA replication, the deposition of new histones, and the introduction of histone modifications and variants. In turn, the chromatin landscape affects several stages during genome replication. Thus, chromatin accessibility is crucial for the initial stages and to specify the location of DNA replication origins with different chromatin signatures. The chromatin landscape also determines the timing of activation during the $\mathrm{S}$ phase. Genome replication must occur fully, but only once during each cell cycle. The re-replication avoidance mechanisms rely primarily on restricting the availability of certain replication factors; however, the presence of specific histone modifications are also revealed as contributing to the mechanisms that avoid re-replication, in particular for heterochromatin replication. We provide here an update of genome replication mostly focused on data from Arabidopsis, and the advances that genomic approaches are likely to provide in the coming years. The data available, both in plants and animals, point to the relevance of the chromatin landscape in genome replication, and require a critical evaluation of the existing views about the nature of replication origins, the mechanisms of origin specification and the relevance of epigenetic modifications for genome replication.
\end{abstract}

Keywords: DNA replication, epigenetics, chromatin, Arabidopsis thaliana, plant.

\section{INTRODUCTION}

The growth and development of a multicellular organism requires thousands of cell divisions to transform the unicellular zygote into the adult body. This is particularly relevant in the case of plants, in which organogenesis occurs entirely in a post-embryonic manner. Remarkably, the integrity of the genetic material of every cell must be maintained throughout all these mitotic divisions. At the same time, a strict requirement is that the genome must be replicated fully and faithfully in order to deliver one exact copy to each daughter cell. Genome duplication occurs during the $S$ phase of the cell cycle, and it is indeed a very risky process. There are numerous sources of potential alterations that need to be prevented or, if they occur, repaired before chromosome segregation at mitosis. Given the fundamental relevance of genome integrity for cell and organismal viability, the process of genome duplication is strictly controlled and coordinated with other cell-cycle events.
It is worth mentioning here that the first demonstration of the semi-conservative nature of DNA and chromosome replication in eukaryotes came with the pioneering work of Taylor et al. (1957) that was published soon after the discovery of the molecular structure of the DNA double helix. Taylor's studies are a must, and provide enlightening reading for anyone coming to the DNA replication field.

One typical feature of all eukaryotic cells is that they possess relatively large genomes of $16000 \mathrm{Mb}$ or more. Replicative DNA polymerases move along their templates at a limited speed, which has been estimated at $\sim 1.5 \mathrm{kbp} \mathrm{m^{-1 }}$ (DePamphilis and Bell, 2011). Assuming this, full replication of a genome starting at a single site would take about a month for Arabidopsis and over 13 years for onion cells. Obviously, this is not the case as the $S$ phase normally takes a few hours to be completed in all eukaryotic cells. The reason is the presence of multiple sites across the genome, called DNA replication origins 
(ORIs), where replication starts to complete the duplication of each replicon unit. Their number seems to be closely and linearly correlated with genome size (Gilbert, 2010; Costas et al., 2011a; DePamphilis and Bell, 2011).

The activation of all ORIs is highly coordinated in time, but most likely also in space, within the S phase; however, the specification of genomic sites where ORls are located, their coordinated timing of activation and the coupling with other DNA-mediated processes (transcription, repair, recombination) are still very poorly understood in molecular terms. An idea is emerging that to understand the process not only the DNA but also the chromatin must be considered. This makes sense, as it is chromatin that is actually duplicated during the $S$ phase. As a consequence, in addition to DNA, all the associated histones that form the nucleosomes and, very importantly, the post-translational modification patterns of histones must be transferred to the daughter chromatids. Thus, many aspects of genome replication control appear to be intimately linked to chromatin events and, in turn, the chromatin landscape also participates in genome replication (Jasencakova and Groth, 2010; Alabert and Groth, 2012). The interaction between the replication machinery and chromatin components is likely the molecular basis of such coordination. In fact, this is only part of an upstream coordination network between chromatin and cell-cycle events throughout G1, S, G2, and mitosis (Desvoyes et al., 2014).

Before entering the description of each stage of genome replication it is worth noting that, as a general rule, most proteins and complexes that participate in the initiation of DNA replication and in replication fork progression are highly conserved in all eukaryotes. The reader is directed to more specialized articles and reviews for details about features of the DNA replication proteins and protein complexes involved in genome replication (for details, see Sanchez et al., 2012). Here we will focus on key aspects of genome replication, with a special emphasis on links with genome-wide chromatin landscapes.

\section{CHROMATIN LICENSING: GAINING ACCESS TO POTENTIAL ORIS}

The first step in setting potential ORIs is the assembly of pre-replication complexes (pre-RC). This must take place once chromosomal segregation has terminated in mitosis and during $\mathrm{G} 1$. The accessibility of pre-RC to potential ORI sites is highly dependent on chromatin and nuclear organization, a process known as 'chromatin licensing' that was introduced conceptually almost 30 years ago (Blow and Laskey, 1986, 1988). Over the years it has received full biochemical, molecular and genetic support (Arias and Walter, 2007). It has been reported that pre-RCs in all systems studied associate with chromatin as early as in the telophase, although this has not been formally demonstrated in plant cells (Sanchez et al., 2012; MacAlpine and Almouzni, 2013).
Chromatin decondensation right after mitosis allows preRC assembly (Gilbert, 2010), although detailed measurements of how long pre-RC loading is allowed during $\mathrm{G} 1$ are not available (Figure 1). Pre-RC components are present in Arabidopsis as well as in the rest of plants for which genome sequences are available (Shultz et al., 2007; Sanchez et al., 2012), and are highly conserved with yeast and mammalian proteins (Table 1). Thus, pre-RCs contain the six subunits ORC1-6 (ORIGIN RECOGNITION COMPLEX 1-6), CDC6 (CELL DIVISION CYCLE 6), CDT1 (CDC10-DEPENDENT TRANSCRIPTION) and the six subunits MCM2-7 (MINICHROMOSOME MAINTENANCE 2-7) complex. A typical feature of Arabidopsis pre-RC proteins is that ORC1, CDC6 and CDT1 are encoded by two separate genes in each case. The respective proteins are highly conserved in amino acid sequence, and it is not yet known whether each of them plays distinct roles or if they act redundantly. In fact, the conservation between plants and animals in pre-RC components can be extended to the rest of proteins that participate in the steps of DNA replication following pre-RC assembly, e.g. replication fork assembly [MCM8, MCM9, MCM10, CDC45 (CELL DIVISION CYCLE 45), and the GINS (GO-ICHINI-SAN; 5-1-2-3 in Japanese) complex] and replication fork progression and maturation of the newly-synthesized DNA [DNA polymerases $A(\alpha), D(\delta)$ and $E(\varepsilon)$ complexes, PCNA (PROLIFERATING CELL NUCLEAR ANTIGEN), RFC (REPLICATION FACTOR C), RPA (REPLICATION PROTEIN A), FEN1 (FLAP STRUCTURE-SPECIFIC ENDONUCLEASE 1) and LIG1 (LIGASE 1)] (Sanchez et al., 2012).

Given the evolutionary conservation of domain structure of pre-RC and DNA replication proteins in all eukaryotes, it is likely that the molecular steps for pre-

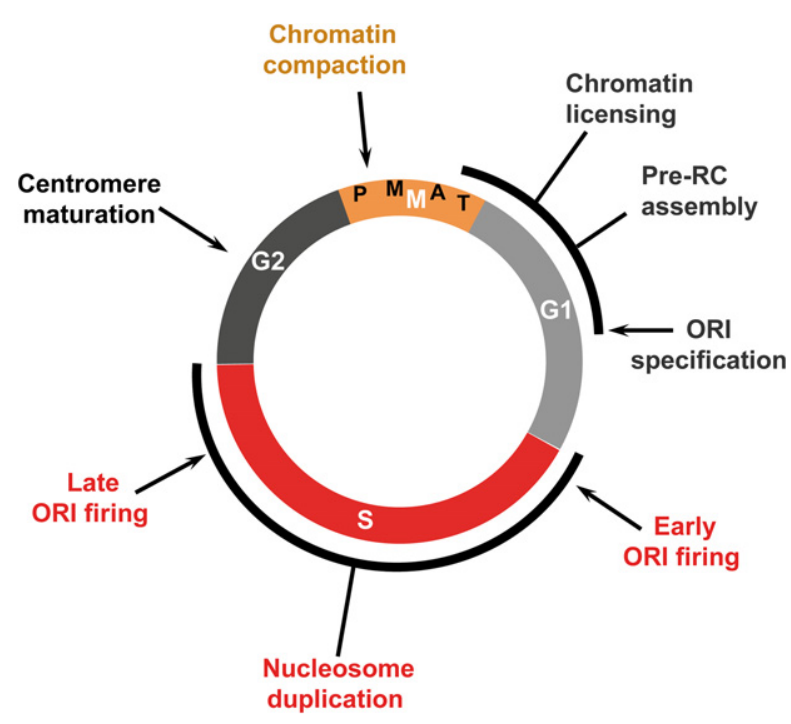

Figure 1. Chromatin-related processes that occur associated with genome replication and segregation during the cell cycle. 
Table 1 A summary of proteins involved in the major stages of chromosomal DNA replication in yeast, Arabidopsis thaliana and human cells

\begin{tabular}{|c|c|c|c|}
\hline $\begin{array}{l}\text { Saccharomyces } \\
\text { cerevisiae }\end{array}$ & $\begin{array}{l}\text { Saccharomyce s } \\
\text { pombe }\end{array}$ & Arabidopsis thaliana & Homo sapiens \\
\hline \multicolumn{4}{|c|}{ Pre-replication compex (pre-RC) } \\
\hline ORC & ORC & ORC & ORC \\
\hline Orc1 & Orc1 & ORC1A (At4g14700) & Orc1/p97 \\
\hline Orc2 & Orc2 & ORC1B (At4g12620) & Orc2/p82 \\
\hline Orc3 & Orc3 & ORC2 (At2g37560) & Orc3/p66 \\
\hline Orc4 & Orc4 & ORC3 (At5g16690) & Orc4/p50 \\
\hline Orc5 & Orc5 & ORC4 (At2g01120) & Orc5L/p50 \\
\hline Orc6 & Orc6 & $\begin{array}{l}\text { ORC5 (At4g29910) } \\
\text { ORC6 (At1g26840) }\end{array}$ & Orc6/p28 \\
\hline Cdc6 & Cdc18 & $\begin{array}{l}\text { CDC6A (At2g29680) } \\
\text { CDc6b (At1g07270) }\end{array}$ & Cdc6 \\
\hline Tah11/Sid2/Cdt1 & Cdt1 & $\begin{array}{l}\text { CDT1A (At2g31270) } \\
\text { CDT1B (At3g54710) }\end{array}$ & Cdt1/RIf-B \\
\hline MCM helicase & MCM helicase & MCM helicase & MCM helicase \\
\hline Mcm2 & Mcm2/Cdc19 & MCM2 (At1g44900) & Mcm2 \\
\hline Mcm3 & $\mathrm{Mcm} 3$ & MCM3 (At5g46280) & Mcm3 \\
\hline Mcm4/Cdc54 & $\mathrm{Mcm} 4 / \mathrm{Cdc} 21$ & MCM4 (At2g16440) & Mcm4 \\
\hline Mcm5/Cdc46/Bob1 & Mcm5/Nda4 & MCM5 (At2g07690) & Mcm5 \\
\hline Mcm6 & Mcm6/Mis5 & MCM6 (At5g44635) & Mcm6 \\
\hline \multirow[t]{4}{*}{$\mathrm{Mcm} 7 / \mathrm{Cdc} 47$} & Mcm7 & MCM7 (At4g02060) & $\begin{array}{l}\text { Mcm7 } \\
\text { Gmnn/Geminin }\end{array}$ \\
\hline & & MCM9 (At2g14050) & Mcm9 \\
\hline & & HAM1 (At5g64610) & Hbo1 \\
\hline & & HAM2 (At5g09740) & \\
\hline \multicolumn{4}{|c|}{ Replication fork assembly } \\
\hline & & MCM8 (At3g09660) & Mcm8 \\
\hline Mcm10/Dna43 & Mcm10/Cdc23 & MCM10 (At2g20980) & Mcm10 \\
\hline Cdc45 & Cdc45/Goa1/ & CDC45 (At3g25100) & Cdc45 \\
\hline GINS complex & GINS complex & GINS complex & GINS complex \\
\hline Sld5/Cdc105 & Sld5 & SLD5 (At5g49010) & Gins4 \\
\hline Psf1/Cdc101 & Psf1 & PSF1 (At1g80190) & Gins1 \\
\hline Psf2/Cdc102 & Psf2 & PSF2 (At3g12530) & Gins2 \\
\hline Psf3/Cdc103 & Psf3 & PSF3 (At1g19080) & Gins3 \\
\hline \multicolumn{4}{|l|}{ Replication fork } \\
\hline DNA Pol- $\alpha$ & DNA Pol- $\alpha$ & DNA Pol- $\alpha$ & DNA Pol- $\alpha$ \\
\hline Pol1/Cdc17/Crt5 & Pol1 & POLA1 (At5g67100) & PolA/p180 \\
\hline Pol12 & Spb70/Pol12 & POLA2 (At1g67630) & PolA2/p68 \\
\hline DNA primase & DNA primase & DNA primase & DNA primase \\
\hline Pri1 & Spp1 & POLA3/PRI1 (At1g67320) & Prim1/p48 \\
\hline Pri2 & Spp2 & POLA4/PRI2 (At5g41880) & Prim2a/p58 \\
\hline DNA Pol- $\delta$ & DNA Pol- $\delta$ & $D N A P o l-\delta$ & DNA Pol- $\delta$ \\
\hline Cdc2/Pol3 & Cdc6/Pol3 & POLD1 (At5g63960) & Pold1/p125 \\
\hline Hys2/Pol31 & Cdc1/Mis1 & POLD2 (At2g42120) & Pold2/p50 \\
\hline \multirow[t]{2}{*}{ Pol32 } & Cdc27 & POLD3 (At1g78650) & Pold3/p66 \\
\hline & Cdm1 & POLD4 (At1g09815) & Pold4/p12 \\
\hline DNA Pol- $\varepsilon$ & DNA Pol- $\varepsilon$ & $D N A$ Pol- $\varepsilon$ & DNA Pol- $\varepsilon$ \\
\hline Pol2/Dun2 & Cdc20/Pol2 & POLE1a (At1g08260) & Pole/p261 \\
\hline Dpb2 & Dpb2 & POLE1b (At2g27120) & Pole2/p59 \\
\hline Dpb3 & Dpb3 & POLE2 (At5g22110) & Pole3/p17 \\
\hline Dpb4 & $\mathrm{Dpb} 4$ & $\begin{array}{l}\text { POLE3/DBP3 (gene family) } \\
\text { POLE4 (DBP4 (gene family) }\end{array}$ & Pole4/p12 \\
\hline RPA complex & RPA complex & RPA complex & RPA complex \\
\hline \multirow[t]{2}{*}{ Rfa1/Rpa1 } & Ssb1/Rpa1 & RPA1a (At5g06510) & Rpa1/p70 \\
\hline & & RPA1b (At5g08020) & \\
\hline Rfa2/Buf1/Rpa2 & Ssb2 & RPA1c (At5g45400) & Rpa2/p32 \\
\hline Rfa3 & Ssb3/Rpa3 & RPA1d (At5g61000) & $\mathrm{Rpa3/p14}$ \\
\hline
\end{tabular}


Table 1. (continued)

\begin{tabular}{|c|c|c|c|}
\hline $\begin{array}{l}\text { Saccharomyces } \\
\text { cerevisiae }\end{array}$ & $\begin{array}{l}\text { Saccharomyce } s \\
\text { pombe }\end{array}$ & Arabidopsis thaliana & Homo sapiens \\
\hline & & RPA2a (At2g24490) & \\
\hline & & RPA2b (At3g02920) & \\
\hline & & RPA3a (At3g52630) & \\
\hline & & RPA3b (At4g18590) & \\
\hline \multirow[t]{2}{*}{ Pol30 } & Pcn1 & PCNA1 (At1g07370) & PCNA \\
\hline & & PCNA2 (At2g29570) & \\
\hline RFC complex & RFC complex & RFC complex & RFC complex \\
\hline $\mathrm{Rfc} 1 / \mathrm{Cdc} 44$ & $\mathrm{Rfc} 1$ & RFC1 (At5g22010) & $\mathrm{Rfc} 1 / \mathrm{p} 140$ \\
\hline $\mathrm{Rfc2}$ & $\mathrm{Rfc2}$ & RFC2 (At1g63160) & $\mathrm{Rfc} 2 / \mathrm{p} 40$ \\
\hline $\mathrm{Rfc3}$ & $\mathrm{Rfc3}$ & RFC3 (At5g27740) & $\mathrm{Rfc3/p38}$ \\
\hline $\mathrm{Rfc} 4$ & $\mathrm{Rfc}_{\mathrm{C}}$ & RFC4 (At1g21690) & $\mathrm{Rfc} 4 / \mathrm{p} 37$ \\
\hline Rfc5 & $\operatorname{Rfc5}$ & RFC5 (At1g77470) & $\mathrm{Rfc5/p36}$ \\
\hline Rad27/Erc11/Rth1 & Rad2/Fen1 & FEN1 (At5g26680) & Fen1 \\
\hline Cdc9/Mms8 & Cdc17 & LIG1 (At1g08130) & Lig1 \\
\hline \multicolumn{4}{|l|}{ Chromatin assembly } \\
\hline CAF1 complex & CAF1 complex & CAF1 complex & CAF1 complex \\
\hline Rlf2/Cac1 & Pcf1 & FAS1 (At1g65470) & p150 \\
\hline Cac2 & Pcf2 & FAS2 (At5g64630) & p60 \\
\hline Msi1/Cac3 & Pcf3 & MSI1 (At5g58230) & $\mathrm{p} 48$ \\
\hline HirA & Hip1 & HIRA (At3g44530) & Hira \\
\hline FACT complex & FACT complex & FACT complex & FACT complex \\
\hline Spt16/Cdc68 & Spt16 & SPT16 (At4g10710) & Supt16h/Spt16 \\
\hline Pob3 & Pob3 & SSRP (At3g28730) & Ssrp1 \\
\hline Nhp6 & Nhp6 & & \\
\hline \multirow[t]{2}{*}{ Asf1 } & Cia1 & ASF1A (AT1g66740) & Asf1a/Cia \\
\hline & & ASF1B (At5g38110) & Asf1b/Cia2 \\
\hline \multirow[t]{6}{*}{ Nap1 } & Nap1 & NAP $1 ; 1$ (At4g26110) & Nap1L1 to Nap1L5 \\
\hline & & NAP1;2 (At2g19480) & \\
\hline & & NAP1;3 (At5g56950) & \\
\hline & & NAP1;4 (At3g13782) & \\
\hline & & NRP1 (At1g74560) & \\
\hline & & NRP2 (At1g18800) & \\
\hline \multirow[t]{12}{*}{ Hta1, Hta2 } & Hta1, Hta2 & Canonical H2A & H2a (H2afb1, \\
\hline & & HTA1/H2A.1 (AT5g54640) & $b 2, b 3, j, v, y, z)$ \\
\hline & & HTA2/H2A.2 (AT4g27230) & \\
\hline & & HTA10/H2.10 (AT1g51060) & \\
\hline & & HTA13/H2A.13 (At3g20670) & $\mathrm{H} 2 \mathrm{afx} / \mathrm{H} 2 \mathrm{ax}$ \\
\hline & & Variant $H 2 A$ & \\
\hline & & HTA3/H2A.X.3 (At1g54690) & \\
\hline & & H2A.X.5 (At1g08880) & $\mathrm{H} 2 \mathrm{afz} / \mathrm{H} 2 \mathrm{az}$ \\
\hline & & HTA6/H2A.W.6 (At5g59870) & \\
\hline & & HTA7/H2A.W.7 (At5g27670) & \\
\hline & & HTA12/H2A.W.12 (At5g02560) & $\mathrm{H} 2 \mathrm{~b}$ (H2bfm, s, wt) \\
\hline & & HTA8/H2A.Z.8 (At2g38810) & \\
\hline \multirow[t]{3}{*}{$\mathrm{Htz} 1 / \mathrm{H} 2 \mathrm{az}$} & Htb1 & HTA9/H2A.Z.9 (At1g52740) & \\
\hline & & HTA11/H2A.Z.11 (At3g54560) & \\
\hline & & HTA4/H2A.Z.4 (At4g13570) & \\
\hline \multirow[t]{10}{*}{ Htb1, Htb2 } & & $H 2 B$ & \\
\hline & & HTB1/H2B.1 (At1g07790) & H3 (Н3f3a, Н3f3c) \\
\hline & & HTA5/H2A.X.5 (At1g08880) & \\
\hline & & HTB1/H2B.1 (At1g07790) & \\
\hline & & HTB2/H2B.2 (At5g22880) & \\
\hline & & HTB3/H2B.3 (At2g28720) & \\
\hline & & HTB4/H2B.4 (At5g59910) & \\
\hline & & HTB5/H2B.5 (At2g37470) & \\
\hline & & HTB6/H2B.6 (At3g53650) & H3.3b (H3f3b) \\
\hline & & HTB7/H2B.7 (At3g09480) & \\
\hline
\end{tabular}


Table 1. (continued)

\begin{tabular}{|c|c|c|c|}
\hline $\begin{array}{l}\text { Saccharomyces } \\
\text { cerevisiae }\end{array}$ & $\begin{array}{l}\text { Saccharomyce s } \\
\text { pombe }\end{array}$ & Arabidopsis thaliana & Homo sapiens \\
\hline & & HTB8/H2B.8 (At1g08170) & \\
\hline & & HTB9/H2B.9 (At3g45980) & \\
\hline & & HTB10/H2B.10 (At5g02570) & \\
\hline & & HTB11/H2B.11 (At3g46030) & \\
\hline \multirow[t]{10}{*}{ Hht1, Hht2 } & Hht1, Hht2, Hht3 & Canonical H3.1 & H4 (Hist1h4a - Hist1H4I) \\
\hline & & HTR1/H3.1 (At5g65360) & \\
\hline & & HTR2/H3.1 (At1g09200) & \\
\hline & & HTR3/H3.1 (At3g27360) & \\
\hline & & HTR9/H3.1 (At5g10400) & \\
\hline & & HTR13/H3.1 (At5g10390) & \\
\hline & & Variant $H 3.3$ & \\
\hline & & HTR4/H3.3 (At4g40030) & \\
\hline & & HTR5/H3.3 (At4g40040) & \\
\hline & & HTR8/H3.3 (At5g10980) & \\
\hline \multirow[t]{7}{*}{ H3.3b (H3f3b) } & & Centromeric H3 & \\
\hline & & HTR12/CENH3 (At1g01370) & \\
\hline & & Unusual H3 & \\
\hline & & HTR6/H3.6 (At1g13370) & \\
\hline & & HTR14/H3.14 (At1g75600) & \\
\hline & & HTR10/H3.10 (At1g19890) & \\
\hline & & HTR7/H3.7 (At1g75610) & \\
\hline \multirow[t]{9}{*}{ Hhf1, Hhf2 } & Hhf1, Hhf2, Hhf3 & $\mathrm{H} 4$ & \\
\hline & & HFO1 (At3g46320) & \\
\hline & & HFO2 (At5g59690) & \\
\hline & & HFO3 (At2g28740) & \\
\hline & & HFO4 (At1g07820) & \\
\hline & & HFO5 (At3g53730) & \\
\hline & & HFO6 (At5g59970) & \\
\hline & & HFO7 (At3g45930) & \\
\hline & & HFO8 (At1g07669) & \\
\hline \multirow[t]{4}{*}{ Hho1 } & & $\mathrm{H} 1$ & H1 (H1fo, nt, oo, x) \\
\hline & & HON1/H1.1 (At1g06760) & \\
\hline & & HON2/H1.2 (At2g30620) & \\
\hline & & HON3/H1.3 (At2g18050) & \\
\hline
\end{tabular}

Codes in parenthesis in the $A$. thaliana column indicate TAIR accessions.

$\mathrm{RC}$ assembly are also conserved in the general rules. Likewise, the molecular interactions between the ORC, CDC6, CDT1 and the MCM2-7 complex are also conserved (Sanchez et al., 2012). Nonetheless, it has been reported that in Arabidopsis the MCM complex remains bound to chromatin throughout the cell cycle, except in mitosis (Shultz et al., 2009). This may reflect plant-specific features, reinforcing the importance of extending these studies to other pre-RC components. It may also be the consequence of MCM binding in non-ORI sites, a possibility that should be addressed in future.

It is important to keep in mind that chromatin licensing for replication is temporally associated with cell fate decisions that occur early in $\mathrm{G} 1$, because both depend on chromatin landscapes of high accessibility. A clear example is that of the homeobox GL2 (GLABRA 2) gene, a master component of cell fate specification of atrichoblasts in the Arabidopsis root epidermis (Schiefelbein et al., 2014). Fluo- rescence in situ hybridization (FISH) experiments revealed that chromatin accessibility at the GL2 locus is cell-cycle regulated, and becomes high after the metaphase, when cells decide on atrichoblast-trichoblast fate (Costa and Shaw, 2006, 2007). Maintenance of an open chromatin state in atrichoblasts and the subsequent (sustained) GL2 expression does not occur in trichoblasts, where chromatin is rapidly converted into a closed, inaccessible state. Interestingly, the pre-RC component CDT1 was shown to increase GL2 expression (Caro et al., 2007), suggesting an association, perhaps more than simply temporal, between genome replication and cell fate acquisition. Further studies are needed to expand these observations and define the molecular interactions, if any, between cell fate and DNA replication machineries and chromatin components (Caro and Gutierrez, 2007).

In animal cells, geminin ( $\mathrm{Gmn}$ ) is a protein that interacts with and inhibits Cdt1 and MCM loading (Wohlschlegel 
et al., 2000; Gillespie et al., 2001; Tada et al., 2001; Maiorano et al., 2004; Xouri et al., 2007; Miotto and Struhl, 2010). In addition to this DNA replication role, Gmn affects the expression of the Hox and Six3 homeodomain genes involved in the expression of neurodifferentiation genes (Del Bene et al., 2004; Luo et al., 2004). Therefore, Gmn competes for chromatin factors to regulate gene expression and Cdt1. In this context, the identification of GEM (GL2 EXPRESSION MODULATOR) in Arabidopsis as a CDT1-interacting factor that participates in pre-RC assembly for DNA replication makes the similarity with animal Gmn unavoidable; however, it must be emphasized that GEM and Gmn are totally unrelated proteins from a structural point of view, although they seem to impinge on the same two processes (Caro and Gutierrez, 2007). This reinforces the relevance of the chromatin accessibility window very early in the cell cycle.

\section{HOW DOES THE CHROMATIN LANDSCAPE AFFECT ORI SPECIFICATION?}

One major and still unsolved question in the DNA replication field is how pre- $\mathrm{RC}$ assembly is directed to chromatin. This has been approached in different models, and the initial, and apparently disparate, outcome of these studies seems to be crystallizing in an emerging view pointing to the chromatin landscape as a major player in the mechanism. Early studies in budding yeast (Saccharomyces cerevisiae) revealed that the location of pre-RC assembly in the genome was strictly defined in a DNA sequence-specific manner. Thus, pre-RC has a strong affinity for the autonomously replicating sequence (ARS, an 11-bp sequence that is sufficient for pre-RC binding; DePamphilis and Bell, 2011; Mechali, 2010). Still, from the 12000 ARS consensus sequences that exist in the yeast genome, only $\sim 400$ initiate replication. This observation suggests that, although being sequence-dependent, the ORI specification mechanism in yeast contains an additional layer of regulation. Indeed, nucleosome organization was found to be a crucial factor in the origin selection step (Eaton et al., 2010). The use of other models soon revealed that the budding yeast situation is rather unique in nature. In the fission yeast (Schyzosaccharomyces pombe), pre-RC assembly is not mediated by a short and specific DNA sequence, but by $A+T$ richness (Segurado et al., 2003; Heichinger et al., 2006). The increase in genome size in multicellular organisms introduced several constraints because animal and plant cells do not have any indication of sequence specificity for pre-RC binding and assembly. Thus, genome-wide studies in Drosophila (MacAlpine et al., 2004; Eaton et al., 2011) and mammalian (Cadoret et al., 2008; Sequeira-Mendes et al., 2009; Mesner et al., 2013) cells have confirmed that although pre-RC and ORIs are not specified by a DNA sequence, they do not locate at random in the genome. These studies have also revealed that the ORI sites show a large diversity in terms of sequence context, adding complexity to the identification of the signature contributing to ORI specification in multicellular organisms.

In vitro experiments have demonstrated that mammalian ORC binding to DNA is independent of a specific DNA sequence (Vashee et al., 2001; Remus et al., 2004; On et al., 2014); however, pre-RC binding in vivo occurs preferentially at certain genomic sites, suggesting that, at least in multicellular organisms, the chromatin landscape may act as a key determinant for pre-RC assembly at specific sites (Figure 1). In support of this, the site-specific histone acetylation induced by the assembly of a transcription domain is sufficient to select a DNA replication origin (Danis et al., 2004). Moreover, the histone acetylase Hbo1, an Orc1/2-, Cdc6- and Mcm2-interacting protein, acetylates these pre-RC components and is required for the final assembly of the MCM complex to complete pre-RC formation (lizuka and Stillman, 1999; Burke et al., 2001; lizuka et al., 2006; Miotto and Struhl, 2010). Interestingly, Arabidopsis encodes the HAM1/2 (HISTONE ACETYLASE WITH A MYST DOMAIN) acetylases, homologous to the human Hbo1 in their MYST domain, which may perform similar roles in pre-RC assembly.

It must be kept in mind that whatever the mechanism that functions to direct pre-RC to specific genomic sites, only a relatively small fraction of these ORC-bound genomic sites initiate replication in a given cell cycle. Besides providing robustness to the system with a backup set of ORls in the case of replicative stress, this can be also related to the observation that several ORC subunits have non-replicative functions (reviewed in Sanchez et al., 2012; Scholefield et al., 2011).

The challenge to identify the signature of ORIs in the genome, which seems to involve both DNA sequence and chromatin signals, is a fundamental aspect of DNA replication control. Learning the combination of molecular features in DNA and chromatin that confer a given genomic site the capacity to function as an ORI would be a major advance. Genome-wide studies have served to demonstrate the association of ORIs with their chromatin landscape. An Arabidopsis 'originome', which is the collection of all possible ORIs detectable in a given experimental setting, e.g. Arabidopsis cultured cells, has recently been obtained (Costas et al., 2011b). This study identified 1500 ORls that, based on the protocol used (pulse-labeling with BrdU of cells synchronized at the G1/S boundary), are likely to be enriched in ORls active in early $\mathrm{S}$ phase. The meta-analysis revealed that the putative initiation sites, i.e. the midpoint of $\mathrm{ORI}$ regions $( \pm 100 \mathrm{nt})$, tend to colocalize with the $5^{\prime}$ end of genic regions, are slightly enriched in $\mathrm{G}+\mathrm{C}$ content, and show a relatively low cytosine methylation $(5 \mathrm{mC})$ level. $\mathrm{H} 3 \mathrm{~K} 4 \mathrm{me} 2$ and $\mathrm{H} 3 \mathrm{~K} 4 \mathrm{me} 3$ are histone modifications also associated with Arabidopsis ORIs, whereas $\mathrm{H} 3 \mathrm{~K} 4 \mathrm{me} 1$ is not. Furthermore, as expected from 
the anticorrelation between $5 \mathrm{mC}$ and the histone $\mathrm{H} 2 \mathrm{~A} . \mathrm{Z}$ variant (Zilberman et al., 2008), Arabidopsis ORls also appear to be enriched in H2A.Z. Further studies also revealed that Arabidopsis ORIs colocalize with regions of high nucleosome density, histone H3.1 and H3.3 (Stroud et al., 2012b). As the association of H2A.Z and H3.3 in the same nucleosome confers instability (Jin and Felsenfeld, 2007), it is conceivable that the colocalization of H2A.Z and $\mathrm{H} 3.3$ with $\mathrm{ORI}$ sites may contribute to establish regions of more accessible chromatin and favor the binding of pre-RC components. Remarkably, most if not all of the chromatin features of Arabidopsis ORIs are also typical of animal ORls, including histone modifications (Cadoret et al., 2008; Sequeira-Mendes et al., 2009; Karnani et al., 2010) and nucleosome enrichment (Lombrana et al., 2013). This probably reveals that mechanisms emerged early in the evolution of multicellular organisms have been maintained in the more recent lineages (Table 2).

Immunofluorescence experiments have demonstrated that an increase in histone acetylation correlates with the S phase in several plants (Jasencakova et al., 2001, 2003; Mayr et al., 2003). This has been confirmed in genomic studies where ORIs were found to associate with sites enriched for H4K5K8K12K16ac (Sanchez and Gutierrez, 2009; Costas et al., 2011b). In addition to this correlation, histone acetylation is relevant to define replication timing (Lee et al., 2010; Costas et al., 2011a; see below). In other eukaryotes a correlation between histone acetylation, ORI specification and replication timing has been reported (Vo- gelauer et al., 2002; Aparicio et al., 2004; Danis et al., 2004; Hartl et al., 2007; Schwaiger et al., 2009).

Although the preferential association of ORIs with certain histone modifications is clear, it is also true that a considerable number of ORIs are located in places with very different combinations of marks. In an effort to rationalize the histone modification data along the genome, several epigenome maps of Arabidopsis chromosome 4 were analyzed to classify the entire length into four main chromatin states: active, repressed, silent, and intergenic domains (Roudier et al., 2011).

A subsequent study comprehensively analyzed the Arabidopsis genome landscape using 15 epigenetic modifications, the histone H3.1 and H3.3 content, and DNA features, e.g. skew (Sequeira-Mendes et al., 2014). This allowed the identification of prevalent combinations of chromatin features or signatures that define nine distinct chromatin states. The different patterns also characterized functional elements in the genome, such as promoters and transcriptional start sites (TSSs), potential enhancers, active and repressed transcriptional units, polycomb group (PcG)-regulated regions, intergenic domains, and two classes of heterochromatin (based on A + T content; SequeiraMendes et al., 2014).

This information on relatively few chromatin states that cover the entire genome, as well as their topographical relationships, should be instrumental to determine the precise signature of different types of ORIs. Before full details in this direction are available, what seems to be

Table 2 A summary of features associated with DNA replication origins in yeast, Drosophila melanogaster, Arabidopsis thaliana and mammalian cells ${ }^{\mathrm{a}}$

\begin{tabular}{|c|c|c|c|c|c|}
\hline & $\begin{array}{l}\text { Saccharomyces } \\
\text { cerevisiae }\end{array}$ & $\begin{array}{l}\text { Saccharomyces } \\
\text { pombe }\end{array}$ & $\begin{array}{l}\text { Drosophila } \\
\text { melanogaster }\end{array}$ & $\begin{array}{l}\text { Arabidopsis } \\
\text { thaliana }\end{array}$ & Mammals \\
\hline DNA consensus sequence & Yes & No & No & No & No \\
\hline ORC sequence specificity & Yes & No & No & No & No \\
\hline GC content & Low & Low & High & High & High \\
\hline G quadruplexes & No & No & Yes & $\mathrm{N} / \mathrm{A}$ & Yes \\
\hline Genomic location & $\begin{array}{l}\text { Mostly } \\
\text { intergenic }\end{array}$ & $\begin{array}{l}\text { Mostly } \\
\text { intergenic }\end{array}$ & $\begin{array}{l}\text { Mostly transcription } \\
\text { units }\end{array}$ & $\begin{array}{l}\text { Mostly transcription } \\
\text { units }\end{array}$ & $\begin{array}{l}\text { Mostly transcription } \\
\text { units }\end{array}$ \\
\hline \multirow[t]{5}{*}{ Chromatin marks } & $\mathrm{H} 3 \mathrm{~K} 4 \mathrm{me} 2$ & & & & \\
\hline & H3K36me1 & $\mathrm{N} / \mathrm{A}$ & $\mathrm{H} 3.3$ & $\mathrm{H} 3 \mathrm{~K} 4 \mathrm{me} 2$ & H4K20me1 \\
\hline & $\mathrm{H} 3 \mathrm{ac}$ & & H3ac & $\mathrm{H} 3 \mathrm{~K} 4 \mathrm{me} 3$ & $\mathrm{H} 4 \mathrm{ac}$ \\
\hline & $\mathrm{H} 4 \mathrm{ac}$ & & $\mathrm{H} 4 \mathrm{ac}$ & $\mathrm{H} 4 \mathrm{~K} 5 \mathrm{ac}$ & \\
\hline & & & & H2A.Z & \\
\hline \multirow{3}{*}{$\begin{array}{l}\text { Association with } \\
\text { nucleosome-depleted } \\
\text { regions }\end{array}$} & Yes & Yes & Yes & $\mathrm{N} / \mathrm{A}$ & Yes \\
\hline & & (Lantermann et al., 2010) & & & \\
\hline & & No (Soriano et al., 2013) & & & \\
\hline
\end{tabular}

$\mathrm{N} / \mathrm{A}$ - no available data.

${ }^{a}$ References for this table: general (Sequeira-Mendes and Gomez, 2012; Leonard and Mechali, 2013; MacAlpine and Almouzni, 2013); S. cerevisiae (Field et al., 2008; Pryde et al., 2009; Eaton et al., 2010; Unnikrishnan et al., 2010; Rizzardi et al., 2012); S. pombe (Lantermann et al., 2010; Givens et al., 2012; Xu et al., 2012; Mojardin et al., 2013; Soriano et al., 2013); D. melanogaster (Aggarwal and Calvi, 2004; Macalpine et al., 2010; Cayrou et al., 2011, 2012; Liu et al., 2012); A. thaliana (Costas et al., 2011b); mammals (Tardat et al., 2007; Cadoret et al., 2008; Sequeira-Mendes et al., 2009; Miotto and Struhl, 2010; Cayrou et al., 2011, 2012; Besnard et al., 2012). 
clear is that ORIs located in different genomic regions possess different signatures. In other words, ORIs do not have a unique chromatin signature but several chromatin signatures, although they may tend to prefer regions of more open chromatin within the range of each chromatin state.

\section{REPLICATION TIMING: WHEN TO FIRE ORIS?}

The existence of thousands of ORIs working in a cell in each S phase to replicate the large eukaryotic genomes is probably at the basis of the need for temporal control of ORI activation (Bryant, 2010; Mechali, 2010; Jackson et al., 2012; Sanchez et al., 2012). Earlier data using DNA fiber autoradiography revealed that the Arabidopsis genome is organized into two major families, separated according to their activation time during the S phase: early- and latereplicating domains (Van't Hof et al., 1978), a situation similar to other eukaryotes (Jasny and Tamm, 1979; Van't Hof and Bjerknes, 1981; Quelo and Verbelen, 2004; Hiratani et al., 2009; Bryant, 2010; Aparicio, 2013). Studies at the cytological level have been confirmed by genomic approaches that additionally served to link replication timing control with chromatin organization (Lee et al., 2010). The temporal profile of Arabidopsis chromosome 4 was obtained after sorting BrdU-labeled nuclei in the early, mid and late $\mathrm{S}$ phase. Most euchromatin is replicated in early/ mid $S$ phase, whereas heterochromatin (and the remaining euchromatin) is replicated later. As in the case of ORI specification, the control of replication timing seems to be also closely associated with a particular chromatin landscape. Early/mid replicating regions correspond to open chromatin states enriched in $\mathrm{H} 3 \mathrm{~K} 56 \mathrm{ac}$ and, as expected, depleted in $\mathrm{H} 3 \mathrm{~K} 9 \mathrm{me} 2$ and $5 \mathrm{mC}$, typical marks of heterochromatin, which is enriched in late-replicating regions.

$\mathrm{H} 3 \mathrm{~K} 56 \mathrm{ac}$ is also associated with initiation zones within patches of heterochromatin; however, a direct link with or requirement for $\mathrm{H} 3 \mathrm{~K} 56 \mathrm{ac}$ in $\mathrm{ORI}$ activation is still missing. It must be noted that this histone modification plays a crucial role in nucleosome deposition past the sites of DNA synthesis, both during replication and repair (Han et al., 2007; Chen et al., 2008; Li et al., 2008). An involvement of this mark in histone turnover at promoters has also been reported (Rufiange et al., 2007).

\section{THE RESTRICTION TO REPLICATE ONCE PER CELL CYCLE}

The common situation is that an activation event of a given ORI results in the replication of a genomic region, $\sim 10$ $200 \mathrm{~kb}$ in length, called a replicon unit. It is of primary importance for genome integrity that each genomic region is duplicated once in every cell cycle (only once and not less than or more than once). Otherwise, should multiple initiation events occur at the same ORI in the same $S$ phase, a genomic region would become over-replicated. On the contrary, failure in activating some ORIs could lead to under-replicated regions. In both cases, they would have deleterious consequences during chromosome segregation. It is worth noting that endoreplication is not a case of altered function of the re-replication control, since during the endocycle, full genome replication occurs in each cycle, instead of an abnormal re-replicated genome part (Edgar et al., 2014). The major mechanism evolved to prevent re-replication consists of the regulation of CDK (CYCLIN DEPENDENT KINASE)/cyclin activity during the cell cycle. As CDK/cyclin activity is low, the pre-RCs can be loaded and selected for activation, processes that are prevented once CDK/cyclin activity increases (Arias and Walter, 2007), ensuring the firing of ORIs once per cell cycle. Therefore, the strategies used to avoid genome re-replication rely on changing the subcellular localization of some pre- $\mathrm{RC}$ components, targeting them for proteasome degradation, or inhibiting their function by interaction with other proteins, with geminin being the more highly characterized protein. In the case of Drosophila, geminin has been implicated in controlling heterochromatin re-replication (Ding and MacAlpine, 2010).

These mechanisms have not been yet identified in plants. As it occurs in animal cells, where the mechanisms of re-replication control are species-specific, it is also likely that a variety of mechanisms have evolved in plants. Furthermore, based on the conservation of pre-RC components and of the cyclic changes in CDK/cyclin activity in the plant cell cycle, it is also likely that the mechanisms controlling re-replication in plants are similar, suggesting that they are very ancient in evolution. In any case, animal geminin seems to be an animal invention, as plants lack a geminin homologous protein (Caro and Gutierrez, 2007); however, a role of the plant CDT1interacting protein GEM in re-replication control has not yet been explored.

More recently, different regulatory layers that rely on chromatin landscapes have been reported. Pre-RC assembly at ORIs in animal cells needs H4K20me1, a modification introduced by the Set7 histone methyltransferase and removed by PHF8 (PHD FINGER PROTEIN 8) demethylase (Yang and Mizzen, 2009; Tardat et al., 2010). In this case, soon after ORI activation, Set7 is degraded by the proteasome in a PCNA (PROLIFERATING CELL NUCLEAR ANTIGEN)- and Cul (CULLIN)-Ddb1 (DNA DAMAGE BINDING PROTEIN 1)-dependent manner and, as a consequence, the levels of H4K20me1 fall sharply (Oda et al., 2009; Liu et al., 2010; Tardat et al., 2010). Immunofluorescence experiments in Arabidopsis have detected H4K20me3 in euchromatin, whereas $\mathrm{H} 4 \mathrm{~K} 20$ me 1 is restricted to heterochromatin (reviewed in Desvoyes et al., 2010; Fuchs et al., 2006; Sanchez et al., 2008); however, the presence of any form of H4K20 methylation has been questioned in Arabidopsis (Zhang et al., 2007). Therefore, a potential role of H4K20 methylation in modulating re-replication needs to be carefully reevaluated in the future. 
Clearer and more direct evidence involving a histone modification in the avoidance of re-replication has been recently reported. H3K27me1, a typical mark of heterochromatin, is deposited by the methyltransferases ATXR5 and ATXR6 (ARABIDOPSIS TRITHORAX RELATED PROTEIN 5 and 6), which are transcriptional E2F targets and interactors of PCNA (Raynaud et al., 2006; Jacob et al., 2009). Leaf cells of the atxr5 atxr6 double mutant show a significant increase in the content of pericentromeric sequences, as revealed by deep sequencing of genomic DNA extracted from nuclei of various ploidy levels (Jacob et al., 2010). As a large fraction of extra DNA is located at specific loci within heterochromatic regions it seems that a certain level of H3K27me1 is needed to prevent heterochromatin re-replication. It is interesting that the re-replication phenotype of the atxr5 atxr6 mutant is partially suppressed by mutations that reduce $5 \mathrm{mC}$ levels, such as ddm1, met1 or cmt3 (Stroud et al., 2012a). A step for the future will be to determine whether the loci enriched in re-replicated DNA actually correspond to active ORIs, an approach that will require solving the challenge of identifying ORIs in whole organisms. Also, an unanswered question is how the presence of H3K27me 1 is sensed and transmitted to the re-replication control pathway. One possibility is that an H3K27me1-specific protein reader binds and signals downstream to prevent further association of the pre-RC and/or its activation. Alternatively, the mechanism may depend on protein degradation of enzymes involved in H3K27me1 deposition, as has been demonstrated for the Set7 [SET domain: Su(var)3-3, Enhancer of Zeste, Trithorax] methylase. Indirect results point to a complex pathway responsible for the function of H3K27me1 in re-replication control. This mark occurs selectively on the canonical histone H3.1 by ATXR5 because H3.3 cannot accommodate it into the catalytic pocket because of steric hindrance provoked by a threonine in $\mathrm{H} 3.3$ (alanine in H3.1; Jacob et al., 2014). This is consistent with the enrichment in H3.1 observed in heterochromatin (Stroud et al., 2012b; Wollmann et al., 2012). Some CDK/cyclin activity may also participate in the signaling cascade, as indirectly suggested by the enhanced phenotype of the atxr5 atxr6 mutant when the CDK inhibitor CDK5 is overexpressed (Jegu et al., 2013).

\section{CHROMATIN REPLICATION}

The process of genome replication requires the complex macromolecular organization of chromatin to be disrupted, either completely or partially, every time that the DNA replication advances. Then, chromatin must be reassembled again past the fork. This is a consequence of the specificity of replicative DNA polymerases to use naked DNA as a substrate. Thus, nucleosomes must be removed ahead of the replication fork and reassembled once the fork passes. The deposition of histone onto newly synthesized DNA does not occur in a passive association manner but is actively carried out by highly specialized histone chaper- ones, which are highly conserved in yeast, plants and animals (Table 1).

Two major classes of chaperones, NAP and NRP (Galichet and Gruissem, 2006; Zhu et al., 2006), as well as CAF1 (CHROMATIN ASSEMBLY FACTOR 1; Das et al., 2010; Polo and Almouzni, 2006; Ramirez-Parra and Gutierrez, 2007b), are in charge of depositing either histone $\mathrm{H} 2 \mathrm{~A}-\mathrm{H} 2 \mathrm{~B}$ or $\mathrm{H} 3-$ H4 dimers, respectively (Figure 1). In fact, CAF1 specifically transfers dimers containing the canonical H3.1 protein in a replication-dependent manner. Once it is introduced into the newly assembled nucleosome, histones $\mathrm{H} 2 \mathrm{~A}$ and $\mathrm{H} 3$ can be replaced by histone variants, a process that normally has consequences in gene expression and chromatin regulation. Thus, $\mathrm{H} 3.1$ is exchanged for the $\mathrm{H} 3.3$ variant by the HIRA (HISTONE REPRESSOR A) complex (Tagami et al., 2004; Duc et al., 2015) through a mechanism that is independent of DNA replication. There are other $\mathrm{H} 3$ chaperones identified in mammalian cells that exchange $\mathrm{H} 3.3$ in certain chromosomal locations. Some of them, e.g. putative ATRX (Alpha thalasemia/mental retardation/syndrome X-linked) and DEK proteins (Otero et al., 2014; Waidmann et al., 2014), are present in Arabidopsis. Recently, experimental data on DEK3 was reported showing that it is important to modulate the expression of downstream target genes relevant for the stress response (Waidmann et al., 2014). Although it is considered within the chaperone class, ASF1 (ANTI-SILENCING FACTOR 1) actually functions as a stock of $\mathrm{H} 3-\mathrm{H} 4$ dimers (Zhu +2006$)$ before transferring them to either CAF1 or HIRA, depending on whether it is formed with $\mathrm{H} 3.1$ or $\mathrm{H} 3.3$, respectively. The $\mathrm{H} 2 \mathrm{~A}$ protein is also frequently replaced by $\mathrm{H} 2 \mathrm{~A} . \mathrm{Z}$, with the help of the SWR1 (SWI2/SNF2 RELATED 1) chaperone complex (March-Diaz and Reyes, 2009). The H2A.Z variant has been implicated in immunity (Lazaro et al., 2008), repair and recombination (Rosa et al., 2013), and temperature sensing (Kumar and Wigge, 2010).

The biochemistry of chromatin replication at the fork has been largely delineated in mammalian cells (Alabert and Groth, 2012; Alabert et al., 2014). Given the similarities between most of the replication proteins in plants and animals, it is likely that the same general trends apply in all eukaryotes; however, it is at the regulatory level that differences may occur, as well as the phenotypic consequences of altered chromatin replication resulting from mutations in histone and chaperone genes. These disparities may be explained by the distinct developmental strategies. Studies in this direction are very scarce in animals because most mutations are embryonic-lethal, thus preventing easy phenotypic analysis in the adult. On the contrary, plants are very versatile and several hypomorphic mutations in chaperone-encoding genes have been described that are compatible with plant development and viability.

The relevance of histone chaperone beyond the step of nucleosome assembly or histone exchange is revealed by 
the pleiotropic phenotypes observed in chaperone mutants. Thus chaperones impact on cell division and organogenesis, and, in turn, in many cases their expression is cell-cycle regulated.

Arabidopsis contains two ASF1 genes ( $A$ and $B$ ), which are E2F targets and act redundantly during development (Zhu et al., 2011; Lario et al., 2013). Vegetative growth is severely impaired because of cell division arrest; however, this is compensated by an increase in cell enlargement that, in this case, does not depend on an increase in nuclear ploidy by endoreplication (Zhu et al., 2011). The phenotypic effects of the loss of function of ASF1 must be related to its biochemical activities of maintaining a stock of $\mathrm{H} 3-\mathrm{H} 4$ dimers, which are likely to be degraded when they are not bound to any chaperone.

Mutants in the three subunits of CAF1 are available. Still, only the two larger subunits (FASCIATA 1 and FASCIATA 2; FAS1 and FAS2) are directly related to chaperone function, because the smaller subunit MSI 1 (MULTICOPY SUPPRESSOR 1) is also found in other protein complexes (Ach et al., 1997; Ausin et al., 2004). Interaction with H3-H4 dimers is mediated by the large subunit FAS1 (Ridgway and Almouzni, 2000). Similar to that, the ASF1 genes, FAS1, FAS2 and MSI1, are all E2F targets (Ramirez-Parra and Gutierrez, 2007a), although only FAS1 expression is cell-cycle regulated. Loss of CAF1 activity has various consequences at the cellular and organ level. Heterochromatin is less compact, its structure is lost and transposon elements are reactivated (Ono et al., 2006; Schonrock et al., 2006). This disrupted heterochromatin structure and function is surprisingly independent of the extent of $\mathrm{H} 3 \mathrm{~K} 9 \mathrm{me} 2$ modification, which is maintained at wild-type levels (Ono et al., 2006; Schonrock et al., 2006). Ribosomal rDNA copies in fas 1 mutants are highly reduced and the telomeres are shortened with severe consequences for vegetative growth (Mozgova et al., 2010; Muchova et al., 2015). Perhaps the most striking phenotype at the cellular level is the early and systemic switch of the fas 1 cells to the endoreplication program, reaching ploidy levels much higher than those of wild-type cells (Exner et al., 2006; Kirik et al., 2006; Ono et al., 2006; Ramirez-Parra and Gutierrez, 2007a). As a consequence, organs contain a reduced number of cells, leading to reduced organ size; however, this is very striking in roots but not in leaves, where a clear compensatory mechanism makes cells significantly larger than wild type cells, whereas the leaf size is only about half of the normal size (Ramirez-Parra and Gutierrez, 2007a).

The HIR complex consists of HIRA, UBN (UBINUCLEIN), and CABIN1 (CALCINEURIN BINDING PROTEIN 1), and has been recently identified in Arabidopsis (Duc et al., 2015). Although HIRA functions independently of DNA replication, altered $\mathrm{H} 3.3$ deposition in hira mutants leads to defects in DNA replication at very early stages of mouse development (Lin et al., 2014). This might be a conse- quence of lower chromatin accessibility as a result of reduced H3.3 levels. In plants, the phenotypes described for hira mutants are not directly related to genome instability; however, they exhibit defects in silencing of pericentromeric heterochromatin and lower nucleosome occupancy (Duc et al., 2015). Interestingly, in a fas 1 mutant background, HIRA seems to have the ability to deposit new histones to restore nucleosome density. The consequences of this altered location of histone $\mathrm{H} 3$ along the genome, as well as the impact on development, should be evaluated in the future.

\section{OUTLOOK}

The high evolutionary conservation of replication proteins suggests that their biochemical relationships to form replication complexes, e.g. pre-RC, and to carry out their functions would be very similar, if not identical, across the eukaryotic scale; however, detailed analysis in different eukaryotic model systems, including yeast, animals, and plants, have revealed that major differences exist in the availability of replication components in different cell-cycle phases or cell types. Therefore, regulatory mechanisms have diversified considerably throughout evolution. Thus, learning the different mechanisms of controlling the availability of replication proteins could help understanding their relevance during the replication process. In this context, as chromatin dynamics has many cell cycle- and cell type-specific features during development, it is also expected that studies on the mechanisms of producing and degrading replication proteins should tell us details about chromatin organization, as a result of the interaction between replication proteins and chromatin components.

One of the major aims in the DNA replication field has been the search for a signature that can be associated with the presence of an active ORI. The data obtained in the early days in human oncoviruses and yeasts suggested that a single signature could determine ORI activity. This view has now changed considerably, and increasing evidence points to the existence of multiple signatures that specify ORIs and that are directly related to the location of ORls in the genome. The identification of the landscape of chromatin states, which reduces the complexity of the eukaryotic genome, now available for Arabidopsis, Drosophila and human cells, is helpful to define different ORI types, depending on their genome location and chromatin landscape. A major challenge will be to identify ORI activity in cells of whole organisms, ideally in different proliferating cell types, and correlate them with the chromatin states present in that particular cell system.

In fact, this will be a necessary step towards determining whether the specific set of histone modifications around a given set of ORls is cause or consequence of their activity as ORIs. A future step would be to manipulate the chromatin landscape and analyze the activity of individual ORIs in 
different genomic locations to infer from these data the causal relationship between chromatin modifications and ORI activity. Although this is not trivial, an additional complication to these studies is that normally it is a set of histone modifications, instead of a single one, that defines a particular chromatin state where ORIs can be ascribed.

In human cells, the presence of $\mathrm{H} 4 \mathrm{~K} 20 \mathrm{me}$ is crucial to control re-replication and eventually genome stability. In Arabidopsis, high levels of H3K27me1 are necessary to avoid re-replication in pericentromeric heterochromatin. The question is whether other histone marks typical of certain genome regions are also relevant for re-replication control, either alone or as a consequence of chromatin proteins specifically bound to these marks. In any case, given the post-embryonic nature of plant growth and development, avoiding genome instability through the many successive cell divisions required to generate an adult plant is of primary importance. Directly related to plant development is the transition from the cell cycle to the endoreplication cycle. An unsolved question is whether the chromatin landscape of endoreplicating and proliferating cells is the same. And as a consequence, whether the ORIs used in endoreplicating cells occupy similar genome locations in proliferating cells and have the same chromatin signatures. The use of genomic approaches in combination with cell biology, biochemical, and molecular techniques should produce a significant synergy in future studies of chromatin replication.

\section{ACKNOWLEDGEMENTS}

We thank members of the CG laboratory for insightful discussions. This research has been supported by grant BFU2012-34821 from MINECO and by an institutional grant from Fundacion Ramon Areces to the Centro de Biologia Molecular Severo Ochoa.

\section{REFERENCES}

Ach, R.A., Taranto, P. and Gruissem, W. (1997) A conserved family of WD40 proteins binds to the retinoblastoma protein in both plants and animals. Plant Cell, 9, 1595-1606.

Aggarwal, B.D. and Calvi, B.R. (2004) Chromatin regulates origin activity in Drosophila follicle cells. Nature, 430, 372-376.

Alabert, C. and Groth, A. (2012) Chromatin replication and epigenome maintenance. Nat. Rev. Mol. Cell Biol. 13, 153-167.

Alabert, C., Bukowski-Wills, J.C., Lee, S.B., Kustatscher, G., Nakamura, K., de Lima Alves, F., Menard, P., Mejlvang, J., Rappsilber, J. and Groth, A. (2014) Nascent chromatin capture proteomics determines chromatin dynamics during DNA replication and identifies unknown fork components. Nat. Cell Biol. 16, 281-293.

Aparicio, O.M. (2013) Location, location, location: it's all in the timing for replication origins. Genes Dev. 27, 117-128.

Aparicio, J.G., Viggiani, C.J., Gibson, D.G. and Aparicio, O.M. (2004) The Rpd3-Sin3 histone deacetylase regulates replication timing and enables intra-S origin control in Saccharomyces cerevisiae. Mol. Cell. Biol. 24, 4769-4780.

Arias, E.E. and Walter, J.C. (2007) Strength in numbers: preventing rereplication via multiple mechanisms in eukaryotic cells. Genes Dev. 21, 497 518

Ausin, I., Alonso-Blanco, C., Jarillo, J.A., Ruiz-Garcia, L. and Martinez-Zapater, J.M. (2004) Regulation of flowering time by FVE, a retinoblastomaassociated protein. Nat. Genet. 36, 162-166.
Besnard, E., Babled, A., Lapasset, L., Milhavet, O., Parrinello, H., Dantec, C., Marin, J.M. and Lemaitre, J.M. (2012) Unraveling cell type-specific and reprogrammable human replication origin signatures associated with G-quadruplex consensus motifs. Nat. Struct. Mol. Biol. 19, $837-$ 844.

Blow, J.J. and Laskey, R.A. (1986) Initiation of DNA replication in nuclei and purified DNA by a cell-free extract of Xenopus eggs. Cell, 47, 577-587.

Blow, J.J. and Laskey, R.A. (1988) A role for the nuclear envelope in controlling DNA replication within the cell cycle. Nature, 332, 546-548.

Bryant, J.A. (2010) Replication of Nuclear DNA. Prog. Bot. 71, 25-60.

Burke, T.W., Cook, J.G., Asano, M. and Nevins, J.R. (2001) Replication factors MCM2 and ORC1 interact with the histone acetyltransferase HBO1. J. Biol. Chem. 276, 15397-15408.

Cadoret, J.C., Meisch, F., Hassan-Zadeh, V., Luyten, I., Guillet, C., Duret, L., Quesneville, H. and Prioleau, M.N. (2008) Genome-wide studies highlight indirect links between human replication origins and gene regulation. Proc. Natl Acad. Sci. USA, 105, 15837-15842.

Caro, E. and Gutierrez, C. (2007) A green GEM: intriguing analogies with animal geminin. Trends Cell Biol. 17, 580-585.

Caro, E., Castellano, M.M. and Gutierrez, C. (2007) A chromatin link that couples cell division to root epidermis patterning in Arabidopsis. Nature, 447, 213-217.

Cayrou, C., Coulombe, P., Vigneron, A. et al. (2011) Genome-scale analysis of metazoan replication origins reveals their organization in specific but flexible sites defined by conserved features. Genome Res. 21, 1438-1449.

Cayrou, C., Coulombe, P., Puy, A., Rialle, S., Kaplan, N., Segal, E. and Mechali, M. (2012) New insights into replication origin characteristics in metazoans. Cell Cycle, 11, 658-667.

Chen, C.C., Carson, J.J., Feser, J., Tamburini, B., Zabaronick, S., Linger, J. and Tyler, J.K. (2008) Acetylated lysine 56 on histone H3 drives chromatin assembly after repair and signals for the completion of repair. Cell, 134, 231-243.

Costa, S. and Shaw, P. (2006) Chromatin organization and cell fate switch respond to positional information in Arabidopsis. Nature, 439, 493-496.

Costa, S. and Shaw, P. (2007) 'Open minded' cells: how cells can change fate. Trends Cell Biol. 17, 101-106.

Costas, C., Sanchez, M.P., Sequeira-Mendes, J. and Gutierrez, C. (2011a) Progress in understanding DNA replication control. Plant Sci., 181, 203 209.

Costas, C., de la Paz Sanchez, M., Stroud, H. et al. (2011b) Genome-wide mapping of Arabidopsis thaliana origins of DNA replication and their associated epigenetic marks. Nat. Struct. Mol. Biol. 18, 395-400.

Danis, E., Brodolin, K., Menut, S., Maiorano, D., Girard-Reydet, C. and Mechali, M. (2004) Specification of a DNA replication origin by a transcription complex. Nat. Cell Biol. 6, 721-730.

Das, C., Tyler, J.K. and Churchill, M.E. (2010) The histone shuffle: histone chaperones in an energetic dance. Trends Biochem. Sci. 35, 476-489.

Del Bene, F., Tessmar-Raible, K. and Wittbrodt, J. (2004) Direct interaction of geminin and Six3 in eye development. Nature, 427, 745-749.

DePamphilis, M. and Bell, S. (2011) Genome duplication. Concepts, mechanisms, evolution, and disease. London: Garland Science, Taylor \& Francis Group.

Desvoyes, B., Sanchez, M.P., Ramirez-Parra, E. and Gutierrez, C. (2010) Impact of nucleosome dynamics and histone modifications on cell proliferation during Arabidopsis development. Heredity, 105, 80-91.

Desvoyes, B., Fernandez-Marcos, M., Sequeira-Mendes, J., Otero, S., Vergara, Z. and Gutierrez, C. (2014) Looking at plant cell cycle from the chromatin window. Front. Plant Sci. 5, 369.

Ding, $\mathbf{Q}$. and MacAlpine, D.M. (2010) Preferential re-replication of Drosophila heterochromatin in the absence of geminin. PLoS Genet. 6, e1001112.

Duc, C., Benoit, M., Goff, S.L., Simon, L., Poulet, A., Cotterell, S., Tatout, C. and Probst, A.V. (2015) The histone chaperone complex HIR maintains nucleosome occupancy and counterbalances impaired histone deposition in CAF-1 mutants. Plant J. 81, 707-722.

Eaton, M.L., Galani, K., Kang, S., Bell, S.P. and MacAlpine, D.M. (2010) Conserved nucleosome positioning defines replication origins. Genes Dev. 24, 748-753.

Eaton, M.L., Prinz, J.A., MacAlpine, H.K., Tretyakov, G., Kharchenko, P.V and MacAlpine, D.M. (2011) Chromatin signatures of the Drosophila replication program. Genome Res. 21, 164-174. 
Edgar, B.A., Zielke, N. and Gutierrez, C. (2014) Endocycles: a recurrent evolutionary innovation for post-mitotic cell growth. Nat. Rev. Mol. Cell Biol. 15, 197-210.

Exner, V., Taranto, P., Schonrock, N., Gruissem, W. and Hennig, L. (2006) Chromatin assembly factor CAF-1 is required for cellular differentiation during plant development. Development, 133, 4163-4172.

Field, Y., Kaplan, N., Fondufe-Mittendorf, Y., Moore, I.K., Sharon, E., Lubling, Y., Widom, J. and Segal, E. (2008) Distinct modes of regulation by chromatin encoded through nucleosome positioning signals. PLoS Comp. Biol. 4, e1000216.

Fuchs, J., Demidov, D., Houben, A. and Schubert, I. (2006) Chromosomal histone modification patterns-from conservation to diversity. Trends Plant Sci. 11, 199-208.

Galichet, A. and Gruissem, W. (2006) Developmentally controlled farnesylation modulates AtNAP1;1 function in cell proliferation and cell expansion during Arabidopsis leaf development. Plant Physiol. 142, 1412 1426.

Gilbert, D.M. (2010) Evaluating genome-scale approaches to eukaryotic DNA replication. Nat. Rev. Genet. 11, 673-684.

Gillespie, P.J., Li, A. and Blow, J.J. (2001) Reconstitution of licensed replication origins on Xenopus sperm nuclei using purified proteins. BMC Bio chem. 2, 15.

Givens, R.M., Lai, W.K., Rizzo, J.M., Bard, J.E., Mieczkowski, P.A., Leatherwood, J., Huberman, J.A. and Buck, M.J. (2012) Chromatin architectures at fission yeast transcriptional promoters and replication origins. Nucleic Acids Res. 40, 7176-7189.

Han, J., Zhou, H., Horazdovsky, B., Zhang, K., Xu, R.M. and Zhang, Z. (2007) Rtt109 acetylates histone $\mathrm{H} 3$ lysine 56 and functions in DNA replication. Science, 315, 653-655.

Hartl, T., Boswell, C., Orr-Weaver, T.L. and Bosco, G. (2007) Developmentally regulated histone modifications in Drosophila follicle cells: initiation of gene amplification is associated with histone $\mathrm{H} 3$ and $\mathrm{H} 4$ hyperacetylation and $\mathrm{H} 1$ phosphorylation. Chromosoma, 116, 197-214.

Heichinger, C., Penkett, C.J., Bahler, J. and Nurse, P. (2006) Genome-wide characterization of fission yeast DNA replication origins. EMBO J. 25 , 5171-5179.

Hiratani, I., Takebayashi, S., Lu, J. and Gilbert, D.M. (2009) Replication timing and transcriptional control: beyond cause and effect-part II. Curr. Opin. Genet. Dev. 19, 142-149.

lizuka, M. and Stillman, B. (1999) Histone acetyltransferase HBO1 interacts with the ORC1 subunit of the human initiator protein. J. Biol. Chem. 274, 23027-23034.

lizuka, M., Matsui, T., Takisawa, H. and Smith, M.M. (2006) Regulation of replication licensing by acetyltransferase Hbo1. Mol. Cell. Biol. 26, 1098 1108.

Jackson, D., Wang, X. and Rudner, D.Z. (2012) Spatio-temporal organization of replication in bacteria and eukaryotes (nucleoids and nuclei). Cold Spring Harb. Perspect. Biol. 4, a010389.

Jacob, Y., Feng, S., LeBlanc, C.A., Bernatavichute, Y.V., Stroud, H., Cokus, S. Johnson, L.M., Pellegrini, M., Jacobsen, S.E. and Michaels, S.D. (2009) ATXR5 and ATXR6 are H3K27 monomethyltransferases required for chromatin structure and gene silencing. Nat. Struct. Mol. Biol. 16, 763-768.

Jacob, Y., Stroud, H., Leblanc, C., Feng, S., Zhuo, L., Caro, E., Hassel, C. Gutierrez, C., Michaels, S.D. and Jacobsen, S.E. (2010) Regulation of heterochromatic DNA replication by histone H3 lysine 27 methyltransferases. Nature, 466, 987-991.

Jacob, Y., Bergamin, E., Donoghue, M.T. et al. (2014) Selective methylation of histone $\mathrm{H} 3$ variant $\mathrm{H} 3.1$ regulates heterochromatin replication. Science, 343, 1249-1253.

Jasencakova, Z. and Groth, A. (2010) Restoring chromatin after replication: how new and old histone marks come together. Semin. Cell Dev. Biol. 21, 231-237.

Jasencakova, Z., Meister, A. and Schubert, I. (2001) Chromatin organization and its relation to replication and histone acetylation during the cell cycle in barley. Chromosoma, 110, 83-92.

Jasencakova, Z., Soppe, W.J., Meister, A., Gernand, D., Turner, B.M. and Schubert, I. (2003) Histone modifications in Arabidopsis- high methylation of $\mathrm{H} 3$ lysine 9 is dispensable for constitutive heterochromatin. Plant J. 33, 471-480

Jasny, B.R. and Tamm, I. (1979) Temporal organization of replication in DNA fibers of mammalian cells. J. Cell Biol. 81, 692-697.
Jegu, T., Latrasse, D., Delarue, M. et al. (2013) Multiple functions of Kiprelated protein5 connect endoreduplication and cell elongation. Plant Physiol. 161, 1694-1705.

Jin, C. and Felsenfeld, G. (2007) Nucleosome stability mediated by histone variants H3.3 and H2A.Z. Genes Dev. 21, 1519-1529.

Karnani, N., Taylor, C.M., Malhotra, A. and Dutta, A. (2010) Genomic study of replication initiation in human chromosomes reveals the influence of transcription regulation and chromatin structure on origin selection. $\mathrm{Mol}$. Biol. Cell, 21, 393-404.

Kirik, A., Pecinka, A., Wendeler, E. and Reiss, B. (2006) The chromatin assembly factor subunit FASCIATA1 is involved in homologous recombination in plants. Plant Cell, 18, 2431-2442.

Kumar, S.V. and Wigge, P.A. (2010) H2A.Z-containing nucleosomes mediate the thermosensory response in Arabidopsis. Cell, 140, 136-147.

Lantermann, A.B., Straub, T., Stralfors, A., Yuan, G.C., Ekwall, K. and Korber, P. (2010) Schizosaccharomyces pombe genome-wide nucleosome mapping reveals positioning mechanisms distinct from those of Saccharomyces cerevisiae. Nat. Struct. Mol. Biol. 17, 251-257.

Lario, L.D., Ramirez-Parra, E., Gutierrez, C., Spampinato, C.P. and Casati, P. (2013) ANTI-SILENCING FUNCTION1 proteins are involved in ultraviolet-induced DNA damage repair and are cell cycle regulated by E2F transcription factors in Arabidopsis. Plant Physiol. 162, 1164 1177.

Lazaro, A., Gomez-Zambrano, A., Lopez-Gonzalez, L., Pineiro, M. and Jarillo, J.A. (2008) Mutations in the Arabidopsis SWC6 gene, encoding a component of the SWR1 chromatin remodelling complex, accelerate flowering time and alter leaf and flower development. J. Exp. Bot. 59, 653-666.

Lee, T.J., Pascuzzi, P.E., Settlage, S.B. et al. (2010) Arabidopsis thaliana chromosome 4 replicates in two phases that correlate with chromatin state. PLoS Genet. 6, e1000982.

Leonard, A.C. and Mechali, M. (2013) DNA replication origins. Cold Spring Harb. Perspect. Biol. 5, a010116.

Li, Q., Zhou, H., Wurtele, H., Davies, B., Horazdovsky, B., Verreault, A. and Zhang, Z. (2008) Acetylation of histone H3 lysine 56 regulates replicationcoupled nucleosome assembly. Cell, 134, 244-255.

Lin, C.J., Koh, F.M., Wong, P., Conti, M. and Ramalho-Santos, M. (2014) Hira-mediated H3.3 incorporation is required for DNA replication and ribosomal RNA transcription in the mouse zygote. Dev. Cell, 30, 268 279

Liu, W., Tanasa, B., Tyurina, O.V. et al. (2010) PHF8 mediates histone H4 lysine 20 demethylation events involved in cell cycle progression. Nature, 466, 508-512.

Liu, J., McConnell, K., Dixon, M. and Calvi, B.R. (2012) Analysis of model replication origins in Drosophila reveals new aspects of the chromatin landscape and its relationship to origin activity and the prereplicative complex. Mol. Biol. Cell, 23, 200-212.

Lombrana, R., Almeida, R., Revuelta, I., Madeira, S., Herranz, G., Saiz, N. Bastolla, U. and Gomez, M. (2013) High-resolution analysis of DNA synthesis start sites and nucleosome architecture at efficient mammalian replication origins. EMBO J. 32, 2631-2644.

Luo, L., Yang, X., Takihara, Y., Knoetgen, H. and Kessel, M. (2004) The cellcycle regulator geminin inhibits Hox function through direct and polycomb-mediated interactions. Nature, 427, 749-753.

MacAlpine, D.M. and Almouzni, G. (2013) Chromatin and DNA replication. Cold Spring Harb. Perspect. Biol. 5, a010207.

MacAlpine, D.M., Rodriguez, H.K. and Bell, S.P. (2004) Coordination of replication and transcription along a Drosophila chromosome. Genes Dev. 18, 3094-3105.

Macalpine, H.K., Gordan, R., Powell, S.K., Hartemink, A.J. and Macalpine D.M. (2010) Drosophila ORC localizes to open chromatin and marks sites of cohesin complex loading. Genome Res. 20, 201-211.

Maiorano, D., Rul, W. and Mechali, M. (2004) Cell cycle regulation of the licensing activity of Cdt1 in Xenopus laevis. Exp. Cell Res. 295, 138-149.

March-Diaz, R. and Reyes, J.C. (2009) The beauty of being a variant: H2A.Z and the SWR1 complex in plants. Mol. Plant, 2, 565-577.

Mayr, C., Jasencakova, Z., Meister, A., Schubert, I. and Zink, D. (2003) Comparative analysis of the functional genome architecture of animal and plant cell nuclei. Chromosome Res. 11, 471-484.

Mechali, M. (2010) Eukaryotic DNA replication origins: many choices fo appropriate answers. Nat. Rev. Mol. Cell Biol. 11, 728-738. 
Mesner, L.D., Valsakumar, V., Cieslik, M., Pickin, R., Hamlin, J.L. and Bekiranov, S. (2013) Bubble-seq analysis of the human genome reveals distinct chromatin-mediated mechanisms for regulating early- and late-firing origins. Genome Res. 23, 1774-1788.

Miotto, B. and Struhl, K. (2010) HBO1 histone acetylase activity is essential for DNA replication licensing and inhibited by geminin. Mol. Cell, 37, $57-$ 66.

Mojardin, L., Vazquez, E. and Antequera, F. (2013) Specification of DNA replication origins and genomic base composition in fission yeasts. J. Mol. Biol. 425, 4706-4713.

Mozgova, I., Mokros, P. and Fajkus, J. (2010) Dysfunction of chromatin assembly factor 1 induces shortening of telomeres and loss of 45S rDNA in Arabidopsis thaliana. Plant Cell 22, 2768-2780.

Muchova, V., Amiard, S., Mozgova, I., Dvorackova, M., Gallego, M.E., White, C. and Fajkus, J. (2015) Homology-dependent repair is involved in 45S rDNA loss in plant CAF-1 mutants. Plant J. 81, 198-209.

Oda, H., Okamoto, I., Murphy, N., Chu, J., Price, S.M., Shen, M.M., TorresPadilla, M.E., Heard, E. and Reinberg, D. (2009) Monomethylation of histone $\mathrm{H} 4$-lysine 20 is involved in chromosome structure and stability and is essential for mouse development. Mol. Cell. Biol. 29, 2278-2295.

On, K.F., Beuron, F., Frith, D., Snijders, A.P., Morris, E.P. and Diffley, J.F. (2014) Prereplicative complexes assembled in vitro support origin-dependent and independent DNA replication. EMBO J. 33, 605-620.

Ono, T., Kaya, H., Takeda, S., Abe, M., Ogawa, Y., Kato, M., Kakutani, T., Mittelsten Scheid, O., Araki, T. and Shibahara, K. (2006) Chromatin assembly factor 1 ensures the stable maintenance of silent chromatin states in Arabidopsis. Genes Cells, 11, 153-162.

Otero, S., Desvoyes, B. and Gutierrez, C. (2014) Histone H3 dynamics in plant cell cycle and development. Cytogenet. Genome Res. 143, 114-124.

Polo, S.E. and Almouzni, G. (2006) Chromatin assembly: a basic recipe with various flavours. Curr. Opin. Genet. Dev. 16, 104-111.

Pryde, F., Jain, D., Kerr, A., Curley, R., Mariotti, F.R. and Vogelauer, M. (2009) H3 k36 methylation helps determine the timing of cdc45 association with replication origins. PLOS ONE, 4, e5882.

Quelo, A.H. and Verbelen, J.P. (2004) Bromodeoxyuridine DNA fiber technology in plants: replication origins and DNA synthesis in tobacco BY-2 cells under prolonged treatment with aphidicolin. Protoplasma, 223 197-202.

Ramirez-Parra, E. and Gutierrez, C. (2007a) E2F regulates FASCIATA1, a chromatin assembly gene whose loss switches on the endocycle and activates gene expression by changing the epigenetic status. Plant Physiol. 144, 105-120.

Ramirez-Parra, E. and Gutierrez, C. (2007b) The many faces of chromatin assembly factor 1 . Trends Plant Sci. 12, 570-576.

Raynaud, C., Sozzani, R., Glab, N., Domenichini, S., Perennes, C., Cella, R., Kondorosi, E. and Bergounioux, C. (2006) Two cell-cycle regulated SETdomain proteins interact with proliferating cell nuclear antigen (PCNA) in Arabidopsis. Plant J. 47, 395-407.

Remus, D., Beall, E.L. and Botchan, M.R. (2004) DNA topology, not DNA sequence, is a critical determinant for Drosophila ORC-DNA binding. EMBO J. 23, 897-907.

Ridgway, P. and Almouzni, G. (2000) CAF-1 and the inheritance of chromatin states: at the crossroads of DNA replication and repair. J. Cell Sci. 113 (Pt 15), 2647-2658.

Rizzardi, L.F., Dorn, E.S., Strahl, B.D. and Cook, J.G. (2012) DNA replication origin function is promoted by $\mathrm{H} 3 \mathrm{~K} 4$ di-methylation in Saccharomyces cerevisiae. Genetics, 192, 371-384.

Rosa, M., Von Harder, M., Cigliano, R.A., Schlogelhofer, P. and Mittelsten Scheid, O. (2013) The Arabidopsis SWR1 chromatin-remodeling complex is important for DNA repair, somatic recombination, and meiosis. Plant Cell, 25, 1990-2001.

Roudier, F., Ahmed, I., Berard, C. et al. (2011) Integrative epigenomic mapping defines four main chromatin states in Arabidopsis. EMBO J. 30, 1928-1938.

Rufiange, A., Jacques, P.E., Bhat, W., Robert, F. and Nourani, A. (2007) Genome-wide replication-independent histone $\mathrm{H} 3$ exchange occurs predominantly at promoters and implicates H3 K56 acetylation and Asf1. Mol. Cell, 27, 393-405.

Sanchez, M.P. and Gutierrez, C. (2009) Arabidopsis ORC1 is a PHD-contain ing $\mathrm{H} 3 \mathrm{~K} 4 \mathrm{me} 3$ effector that regulates transcription. Proc. Natl Acad. Sci. USA, 106, 2065-2070.
Sanchez, M., Caro, E., Desvoyes, B., Ramirez-Parra, E. and Gutierrez, C. (2008) Chromatin dynamics during the plant cell cycle. Semin. Cell Dev. Biol. 19, 537-546.

Sanchez, M.P., Costas, C., Sequeira-Mendes, J. and Gutierrez, C. (2012) DNA replication control in plants. Cold Spring Harb. Perspect. Biol. 4 a010140.

Schiefelbein, J., Huang, L. and Zheng, X. (2014) Regulation of epidermal cell fate in Arabidopsis roots: the importance of multiple feedback loops. Front. Plant Sci. 5, 47.

Scholefield, G., Veening, J.W. and Murray, H. (2011) DnaA and ORC: more than DNA replication initiators. Trends Cell Biol. 21, 188-194.

Schonrock, N., Exner, V., Probst, A., Gruissem, W. and Hennig, L. (2006) Functional genomic analysis of CAF-1 mutants in Arabidopsis thaliana. $J$. Biol. Chem. 281, 9560-9568.

Schwaiger, M., Stadler, M.B., Bell, O., Kohler, H., Oakeley, E.J. and Schubeler, D. (2009) Chromatin state marks cell-type- and gender-specific replication of the Drosophila genome. Genes Dev. 23, 589-601.

Segurado, M., de Luis, A. and Antequera, F. (2003) Genome-wide distribution of DNA replication origins at A+T-rich islands in Schizosaccharomyces pombe. EMBO Rep. 4, 1048-1053.

Sequeira-Mendes, J. and Gomez, M. (2012) On the opportunistic nature of transcription and replication initiation in the metazoan genome. BioEssays, 34, 119-125.

Sequeira-Mendes, J., Diaz-Uriarte, R., Apedaile, A., Huntley, D., Brockdorff, N. and Gomez, M. (2009) Transcription initiation activity sets replication origin efficiency in mammalian cells. PLoS Genet. 5, e1000446.

Sequeira-Mendes, J., Araguez, I., Peiro, R., Mendez-Giraldez, R., Zhang, X., Jacobsen, S.E., Bastolla, U. and Gutierrez, C. (2014) The functional topography of the arabidopsis genome is organized in a reduced number of linear motifs of chromatin states. Plant Cell, 26, 2351-2366.

Shultz, R.W., Tatineni, V.M., Hanley-Bowdoin, L. and Thompson, W.F. (2007) Genome-wide analysis of the core DNA replication machinery in the higher plants Arabidopsis and rice. Plant Physiol. 144, 1697-1714.

Shultz, R.W., Lee, T.J., Allen, G.C., Thompson, W.F. and Hanley-Bowdoin, L. (2009) Dynamic localization of the DNA replication proteins MCM5 and MCM7 in plants. Plant Physiol. 150, 658-669.

Soriano, I., Quintales, L. and Antequera, F. (2013) Clustered regulatory elements at nucleosome-depleted regions punctuate a constant nucleosomal landscape in Schizosaccharomyces pombe. BMC Genom. 14, 813.

Stroud, H., Hale, C.J., Feng, S., Caro, E., Jacob, Y., Michaels, S.D. and Jacobsen, S.E. (2012a) DNA methyltransferases are required to induce heterochromatic re-replication in Arabidopsis. PLoS Genet. 8, e1002808.

Stroud, H., Otero, S., Desvoyes, B., Ramirez-Parra, E., Jacobsen, S.E. and Gutierrez, C. (2012b) Genome-wide analysis of histone H3.1 and H3.3 variants in Arabidopsis thaliana. Proc. Natl Acad. Sci. USA, 109, 5370 5375 .

Tada, S., Li, A., Maiorano, D., Mechali, M. and Blow, J.J. (2001) Repression of origin assembly in metaphase depends on inhibition of RLF-B/Cdt1 by geminin. Nat. Cell Biol. 3, 107-113.

Tagami, H., Ray-Gallet, D., Almouzni, G. and Nakatani, Y. (2004) Histone H3.1 and H3.3 complexes mediate nucleosome assembly pathways dependent or independent of DNA synthesis. Cell, 116, 51-61.

Tardat, M., Murr, R., Herceg, Z., Sardet, C. and Julien, E. (2007) PR-Set7dependent lysine methylation ensures genome replication and stability through S phase. J. Cell Biol. 179, 1413-1426.

Tardat, M., Brustel, J., Kirsh, O., Lefevbre, C., Callanan, M., Sardet, C. and Julien, E. (2010) The histone H4 Lys 20 methyltransferase PR-Set7 regu lates replication origins in mammalian cells. Nat. Cell Biol. 12, 1086 1093.

Taylor, J.H., Woods, P.S. and Hughes, W.L. (1957) The organization and duplication of chromosomes as revealed by autoradiographic studies using tritium-labeled thymidine. Proc. Natl Acad. Sci. USA, 43, 122-128.

Unnikrishnan, A., Gafken, P.R. and Tsukiyama, T. (2010) Dynamic changes in histone acetylation regulate origins of DNA replication. Nat. Struct. Mol. Biol. 17, 430-437.

Van't Hof, J. and Bjerknes, C.A. (1981) Similar replicon properties of higher plant cells with different $\mathrm{S}$ periods and genome sizes. Exp. Cell Res. 136, 461-465.

Van't Hof, J., Kuniyuki, A. and Bjerknes, C.A. (1978) The size and number of replicon families of chromosomal DNA of Arabidopsis thaliana. Chromosoma, 68, 269-285. 
Vashee, S., Simancek, P., Challberg, M.D. and Kelly, T.J. (2001) Assembly of the human origin recognition complex. J. Biol. Chem. 276, 26666-26673.

Vogelauer, M., Rubbi, L., Lucas, I., Brewer, B.J. and Grunstein, M. (2002) Histone acetylation regulates the time of replication origin firing. $\mathrm{Mol}$. Cell, 10, 1223-1233.

Waidmann, S., Kusenda, B., Mayerhofer, J., Mechtler, K. and Jonak, C. (2014) A DEK domain-containing protein modulates chromatin structure and function in arabidopsis. Plant Cell, 26, 4328-4344.

Wohlschlegel, J.A., Dwyer, B.T., Dhar, S.K., Cvetic, C., Walter, J.C. and Dutta, A. (2000) Inhibition of eukaryotic DNA replication by geminin binding to Cdt1. Science, 290, 2309-2312.

Wollmann, H., Holec, S., Alden, K., Clarke, N.D., Jacques, P.E. and Berger, F. (2012) Dynamic deposition of histone variant H3.3 accompanies developmental remodeling of the Arabidopsis transcriptome. PLoS Genet. 8 e1002658.

Xouri, G., Squire, A., Dimaki, M., Geverts, B., Verveer, P.J., Taraviras, S. Nishitani, H., Houtsmuller, A.B., Bastiaens, P.I. and Lygerou, Z. (2007) Cdt1 associates dynamically with chromatin throughout $\mathrm{G} 1$ and recruits Geminin onto chromatin. EMBO J. 26, 1303-1314.
Xu, J., Yanagisawa, Y., Tsankov, A.M. et al. (2012) Genome-wide identification and characterization of replication origins by deep sequencing. Genome Biol. 13, R27.

Yang, H. and Mizzen, C.A. (2009) The multiple facets of histone H4-lysine 20 methylation. Biochem. Cell Biol. 87, 151-161.

Zhang, X., Clarenz, O., Cokus, S., Bernatavichute, Y.V., Pellegrini, M., Goodrich, J. and Jacobsen, S.E. (2007) Whole-genome analysis of histone H3 lysine 27 trimethylation in Arabidopsis. PLoS Biol. 5, e129.

Zhu, Y., Dong, A., Meyer, D., Pichon, O., Renou, J.P., Cao, K. and Shen W.H. (2006) Arabidopsis NRP1 and NRP2 encode histone chaperones and are required for maintaining postembryonic root growth. Plant Cell, 18, 2879-2892.

Zhu, Y., Weng, M., Yang, Y., Zhang, C., Li, Z., Shen, W.H. and Dong, A (2011) Arabidopsis homologues of the histone chaperone ASF1 are crucial for chromatin replication and cell proliferation in plant development. Plant J. 66, 443-455.

Zilberman, D., Coleman-Derr, D., Ballinger, T. and Henikoff, S. (2008) Histone H2A.Z and DNA methylation are mutually antagonistic chromatin marks. Nature, 456, 125-129. 